\title{
The endoscopic picture of upper digestive hemorrages secondary to stromal tumors (GIST). Report of two cases
}

\author{
Bartolomé García Pérez ${ }^{1}$ Rocío García Paredes², Ángel Vargas Acostaํㄹ Emilio Belchí Segura ${ }^{1}$, \\ María Luisa Ortiz Sanchez ${ }^{1}$ and Fernando Carballo Alvarez ${ }^{1}$ \\ ${ }^{1}$ Department of Digestive Diseases. Hospital Universitario Virgen de la Arrixaca. El Palmar, Murcia. Spain. ${ }^{2}$ Unit of \\ Digestive Diseases. Complejo Hospitalario La Mancha Centro. Alcazar de San Juan, Cuidad Real. Spain
}

\section{INTRODUCTION}

Gastrointestinal mesenchymal tumors are infrequent, amounting to 1-3\% of intestinal tumors. The gastrointestinal stromal tumor (GIST) arises from Cajal cells and the majority of them possess special characteristics (1).

These tumors are most commonly sighted in the stomach. The second most frequent location is the small intestine. Only between 3 to $5 \%$ of these specific tumors are found in the duodenum.

\section{CASE REPORTS}

\section{Case 1}

A 74-year-old hypertensive patient with ischemic cardiomyopathy was consulted in the emergency room for experiencing several days of melena like symptoms. Endoscopy was performed, showing a submuscosal tumor around the papillary area. The use of the duodenoscope offered the best view of the tumor, reveling ulceration at its surface (Fig. 1). Ecoendoscopy was able to be done, showing a submuscosal lesion in the second portion of the duodenum (Fig. 2). Areas of necrosis were visible around the interior, solely affecting the muscle layer and leaving the serosa intact. Urgent surgery was performed, extracting the duodenal tumor. The pathological anatomy reported a GIST with a low risk of positive malignance for C-KIT.

\section{Case 2}

A 62-year-old patient with dyslipidemia was admitted with symptoms of melena and hematochezia, while experiencing syncope. Endoscopy was performed, detecting a fistulous orifice in the distal duodenum. An abundant amount of blood was found flowing from (Fig. 3) the detected area. Faced with the hemodynamic instability of the patient, surgical interven-

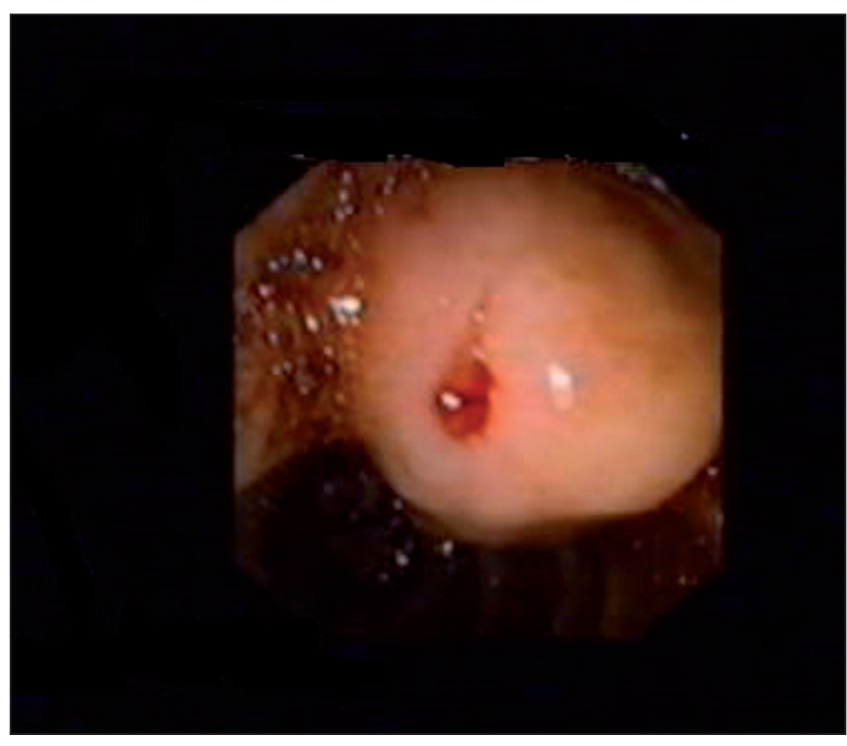

Fig. 1. Ulcerated submucosal tumor

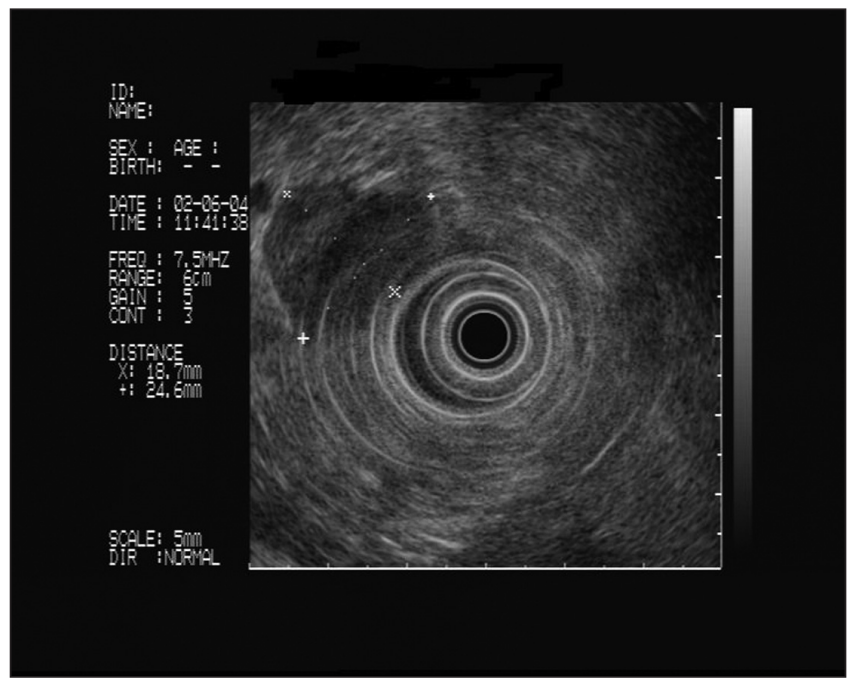

Fig. 2. USE of the tumor 
tion was urgently needed. A $5 \mathrm{~cm}$ tumor with extraparietal growth, blocking the duodenal space, was detected and removed. The histological diagnosis resulted in a GIST.

\section{DISCUSSION}

GISTs usually form between the muscle layer and the mucosa, growing into the intestinal space, the serosa, or possibly in both directions (2). They are most frequent in males, with an average age of 58 years old (3). GISTs can present themselves as digestive hemorrhaging, abdominal pain, palpable masses, invagination or asthenia (4). Although, it is important to note that smaller tumors can be asymptomatic and found causally during routine endoscopies. The duodenal tumors of the second and third portion can be difficult to distinguish if their origin is pancreatic.

Endoscopically, there is no typical image of this type of lesion. They look like extrinsic submucosal/compressed

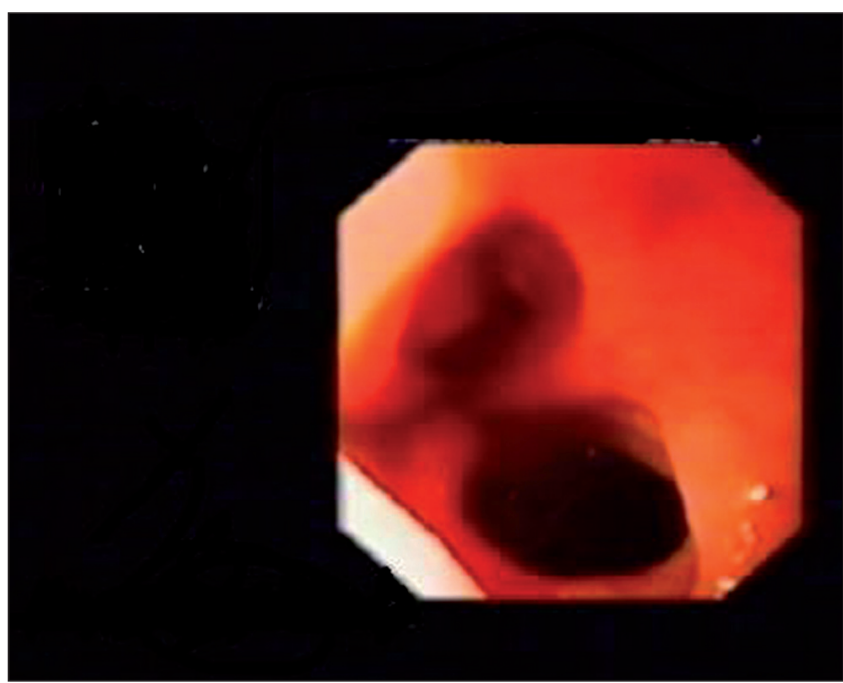

Fig. 3. Huge fistulous orifice due to extraluminal growth of the GIST. tumors. Normally, their biopsy results are negative.

The value of the USE-PAAF is usually limited. However, we can use this procedure to accurately determine the tumor's size, origin and relationship with neighboring structures. These details are fundamental for the surgeon to adequately propose the correct treatment (as seen in case 1). Furthermore, it serves as the election methodology used to differentiate between the submucosal tumors and extrinsic compressions in the digestive tube (5).

The treatment will depend on the tumor's location, size and presence of metastasis.

\section{REFERENCES}

1. $\quad$ Eizaguirre Zarza B, Burgos Bretones JJ. Tumores GIST. Revisión de la literatura. Rev Esp Patol 2006;39:209-18.

2. De Matteo R, Lewis J, Leung D, Mudan S, Woodruf J, Brennan M. Two hundred gastrointestinal stromal tumors. Ann Surg 2000;231:51-8.

3. Miquel Plaza J, Martín de Argila C, Martínez Molina E, González Palacios J, San Juan Benito A, Boixeda de Miquel D. Tumor estromal colónico de características atípicas. Gastroenterol Hepatol 2001;24:7.

4. Alamo Martínez JM, López Bernal F, Galindo Galindo JA, Guerra Bautista JM, Sousa Vaquero C, Cruz Villalba, et al. Pequeño GIST duodenal como causa de hemorragia digestiva masiva en un paciente joven. Cir Esp 2003;73 (4):262-3.

5. Arguello R, Pellisé M, Miquel R. Utilidad de la ultrasonografía endoscópica (USE) en la evaluación de los tumores submucosos y compresiones extrínsecas del tubo digestivo. Gastroenterol Hepatol 2002;25(1):13-8. 